This is a self-archived - parallel published version of this article in the publication archive of the University of Vaasa. It might differ from the original.

\title{
Cloud manufacturing system for sheet metal processing
}

Author(s): Helo, Petri; Hao, Yuqiuge

Title: $\quad$ Cloud manufacturing system for sheet metal processing

Year: $\quad 2017$

Version: Accepted manuscript

Copyright (C) 2017 Taylor \& Francis. This is an Accepted Manuscript of an article published by Taylor \& Francis in Production Planning and Control on 17 May 2017, available online: http://www.tandfonline.com/10.1080/09537287.2017.1309714.

\section{Please cite the original version:}

Helo, P. \& Hao, Y., (2017). Cloud manufacturing system for sheet metal processing. Production Planning and Control, 28(6-8), 524-537. https://doi.org/10.1080/o9537287.2017.1309714 


\title{
Cloud manufacturing system for sheet metal processing
}

\begin{abstract}
Cloud computing is changing the way industries and enterprises run their businesses. Cloud manufacturing is emerging as an approach to transform the traditional manufacturing business model, while helping the manufacturer to align production efficiency with its business strategy, and creating intelligent factory networks that enable collaboration across the whole enterprise. Many production planning and control problems are essentially optimization problems, where the objective is to develop a plan that meets the demand at minimum cost or maximum profit. Because the underlying optimization problem will vary in the different business and operation phases, it is important to think about optimization in a dynamic mechanism and in a number of interlinked sub-problems at the same time. Cloud manufacturing has the potential to offer decision support as a service and medium of communication in production planning and control. To solve these problems and produce collaboration across the supply chain, this paper provides an overview of the state of the art in cloud manufacturing and presents a model of cloud-based production planning and production system for sheet metal processing.
\end{abstract}

Keywords: cloud manufacturing, production control, supply chain, sheet metal.

\section{Introduction}

Changes in the global economy, fierce competition and the rapid development of internet technology are continually stimulating new models of manufacturing that may be appropriate for a particular business. These characteristics require soft hierarchical approaches to operate manufacturing systems (Frayret et al., 2004). The characteristics of this new era of manufacturing industry are agile, networked, sustainable and digitalized processes with temporary collaborations across supply chains. At the same time, the trend towards more geographically distributed manufacturing, coverage of the enterprise chain, and inter-enterprise collaborative business follow an evolution trajectory that leads to the enterprise manufacturing model (Zhou et al., 2011). A number of similar paradigms have emerged in parallel with the intention of solving the challenges of distributed resources, such as holonic manufacturing, agent- 
based intelligent manufacturing, reconfigurable manufacturing, distributed manufacturing, dispersed network manufacturing, and virtual enterprises (Bi et al., 2014; Ford et al., 2012). They all have played a critical role in the development of manufacturing industries, although each definition has its own emphasis. However, there are still many barriers to efficient manufacturing systems and current systems cannot meet the demand for enhanced quality requirements (Ning et al., 2011; Zhang et al., 2014). Fortunately, a more comprehensive and profound solution, i.e. cloud manufacturing, has emerged and has been widely applied in various fields.

Cloud manufacturing is a new type of smart manufacturing system that focuses on service-orientation and knowledge-bases. It aims to provide high efficiency and low energy consumption for manufacturers (Li et al., 2010). During the innovation process in manufacturing industry, the development of ICT (information and communication technology) always plays a crucial role in improving production efficiency and takes full advantage of manufacturing resources (Jiang et al., 2013).

In a cloud manufacturing system, state-of-the-art technologies such as digitalized manufacturing, cloud computing, the Internet of Things (IoT), semantic web, and high-performance computing are integrated. By extending and shifting existing manufacturing and service systems, manufacturing resources and capabilities are virtualized and provided as manufacturing services based on demand. This is achieved by the coordination of local information (e.g. machine loading and performance) and global information (e.g. demand from a market). There are similar forms of coordination in agent-based manufacturing systems (Sikora and Shaw, 1997; Parunak et al., 1997; Frayret et al., 2004). A cloud manufacturing system is a scalable service platform to support cross-enterprise operation and multi-agent collaborative interaction (Zhang et al., 2014). Compared with traditional agent-based manufacturing systems, cloud manufacturing not only improves information and resource sharing, but also aims to improve machine utilization and enable rapid capacity scalability. Moreover, the virtualized resources and capabilities are efficiently shared among different enterprises by unified and centralized intelligent management and operations. Cloud manufacturing supports the whole manufacturing lifecycle with the goal of high quality, flexible and on-demand services at low prices through a networked system (Li et al., 2010).

The motivation of this paper is to outline a cloud manufacturing system for sheet metal processing and to address the challenges and issues that original equipment manufacturers (OEMs) have in production planning and control. The purpose of this paper is to present a cloud-based production planning and control concept for sheet metal manufacturing. This study was conducted in the form of a case study. Twelve domain experts from one company, which is a specialist in sheet metal fabrication machines, were interviewed about their perspective on possible ways to achieve cloud manufacturing by implementing cloud-based production planning and control system. The results of the interview were analyzed, and several requirements were suggested. Based on this case study, a model of cloud-based 
production planning and control system is proposed. Cloud computing technology and physical information fusion technology may benefit manufacturing enterprises.

The remainder of the paper is organized as follows. Section 2 elaborates the relevant studies that were reviewed. Section 3 studies the functional requirements for cloud manufacturing. Section 4 presents the conceptual model and architectural considerations. Section 5 then concludes the paper.

\section{Literature Review}

\subsection{Cloud Manufacturing}

Cloud computing is the next step in the evolution of the Internet and it is the trend of pay-as-you-go utility computing, elasticity, virtualization, grid computing, distributed computing, content outsourcing and Web 2.0 (Xu, 2012). Cloud computing is not a new technical term but a convergence of several existing technologies, such as computing, networking, storage, and powerful management tools (Cisco, 2012). It is considered as a multidisciplinary research field and it enables a new generation of IT and business management. Cloud computing simultaneously provides a paradigm shift of IT (information technology) and business infrastructure (Xu, 2012).

Manufacturing companies need a new platform to fulfill their need for an increasingly IT reliant, globalized, distributed and agile business model. Multinational companies are looking for a solution to dynamically add both tangible and intangible resources for a particular project, while improving plant floor visibility and achieving more efficient processes without having to make incremental investment in their IT resources (Giriraj and Muthu, 2013). Cloud computing infrastructure not only provides the power of virtualization, automation and collaboration to the whole manufacturing supply chain and networked enterprises, but also brings significant financial advantages. While services are becoming inherent characteristics of products, manufacturing industry is gradually transforming from a traditional product-oriented type to a service-oriented one (Huang et al., 2013; Luo et al., 2011). Cloud computing represents a breakthrough concept to achieve the transformation from production-oriented to serviceoriented manufacturing (Xu, 2012; Cheng et al., 2010; Tao et al., 2011), where everything is provided as services: argumentation as a service, design as a service, fabrication as a service, experiment as a service, simulation as a service, management as a service, operation as a service, and so on (Ma et al., 2010).

It is very interesting that many researchers 'borrow' the concept of cloud computing to give rise to 'cloud manufacturing' (CM), which is a manufacturing approach to cloud computing. There are valid reasons and perhaps requirements for manufacturing business to develop towards digitalization and embrace cloud computing ( $\mathrm{Li}$ et al., 2010; Xu, 2012). It is believed that cloud computing can play a 
critical role in establishing linkages between MRP (manufacturing resources planning), ERP (enterprise resource planning) and CRM (customer relationship management) (Xu, 2012). The concept of cloud manufacturing has borrowed some central ideas from earlier work, which should be acknowledged. A standardized framework for co-operation between entities is one of them. Information and resource sharing mechanism in the network has been introduced already in the early 80's by Smith (1980) in the ContractNet system. Shaw (1988) introduced dynamic scheduling for cellular manufacturing systems for networked system. Agent based systems in manufacturing have also introduced rules and negotiations in order to adjust toward requested capacity (Monostori et al 2006). The problems have always been there and the approaches proposed in earlier literature have remained mostly in academic context. The general availability and emergence of cloud technology is able to deliver this type of features for wider audiences. Standardized information models, real-time or close to real-time interfaces between entities and possibility to utilized centralized decision making or local rules are all possible implications.

When cloud manufacturing is discussed, what comes to mind first is the existing networked manufacturing concept, sometimes called internet-based manufacturing or distributed manufacturing, manufacturing grid, virtual manufacturing, and agile manufacturing (Ford et al., 2012; Xu, 2012). All these concepts have common origins, which can be traced back to the 1990s, when the agent based framework for manufacturing systems was proposed to integrate distributed machines and to manage heterogeneous components in a homogeneous fashion (Sikora and Shaw, 1997; Parunak et al., 1997). The distributed manufacturing systems concept was designed to allow optimum decision making on distributed resource usage (Tharumarajah, 2001); virtual manufacturing was designed to realize the actual manufacture process by computer (Zhang et al., 2014); and agile manufacturing appeared in response to changing demand (Wang and Lin, 2009). However, today's networked manufacturing mainly refers to an integration of distributed resources for undertaking a single manufacturing task (Xu, 2012). A resource pool or resource sharing mechanism was proposed in previous coordination formats (Frayet et al., 2004). However, what is lacking in these types of manufacturing regimes are the centralized operation management of the services, choice of different operation modes, and embedded access to manufacturing equipment and resources, without which a seamless, stable, and high quality transaction of manufacturing resource services cannot be guaranteed (Xu, 2012). In the manufacturing system, "control" and "communication (coordination)" are identified to solve distribution problems (Caridi and Cavalieri, 2004; Frayret et al., 2004). The evolution of manufacturing systems needs to be considered from these two dimensions. At present, cloud manufacturing has become a new mode of multi-agent networked manufacturing, and it is evolving significantly in both control and communication approaches. 
Cloud manufacturing contains two important principles: 'integration of distributed resources' and 'distribution of integrated resources'. Xu (2012) defined cloud manufacturing by mirroring The National Institute of Standards and Technology (NIST)'s definition of cloud computing as 'a model for enabling ubiquitous, convenient, on-demand network access to a shared pool of configurable manufacturing resources (e.g., manufacturing software tools, manufacturing equipment, and manufacturing capabilities) that can be rapidly provisioned and released with minimal management effort or service provider interaction.'

Li et al. (2010) introduced the definition of cloud manufacturing to perform larger scale collaborative manufacturing in a research project funded by the National Natural Science Foundation of China. Based on this definition, many cloud manufacturing related studies have been launched, such as Zhang et al. (2014), who further described the key issues for the construction of cloud manufacturing, and Li et al. $(2011 ; 2012)$ who discussed cloud manufacturing and resource encapsulation technology.

ManuCloud is a project in the European Union (EU)'s Seventh Framework Programme (FP7) which is targeted at developing a marketplace for virtualized manufacturing services, supporting on-demand manufacturing scenarios, and achieving the next level of integration of manufacturing networks based on the dynamic interconnection of multiple factories (Yip et al., 2011). It provides users with the ability to utilize the manufacturing capabilities of configurable, virtualized production networks, based on cloud-enabled, federated factories, supported by a set of software-as-a-service applications (Meier et al., 2010).

Manufacturers and their subcontractors develop a close collaborative relationship to improve the coordination of their mutual activities and enhance innovative performance. Trust and contracts have been viewed as two important mechanisms to safeguard business opportunity and maintain a cooperative relationship (Wang et al., 2011). In a cloud manufacturing environment, during the product development process the collaborating agents have to exchange product information, so they should have mutual understanding of that exchange information, and most importantly, they need to trust each other both in communication and information contents in order to improve the quality of their relations (Fatahi Valilai and Houshmand, 2014; Ripamonti and Peraboni, 2010).

Yousif (2014) presents an example showing that in a cloud based collaborative environment, the parties need to go through the authorization process every time before establishing a relationship. Such collaborative environment allows distributed manufacturing to realize competitive advantages by using their existing resources for collaborating with each other. This method can also satisfy the risk control requirements. Similarly in cloud manufacturing, in order to build a trusting environment, it is necessary to embed an authentication and authorization mechanism, a trust evaluation and measurement mechanism, and reliability analysis features into the cloud manufacturing platform ( $\mathrm{He}$ and $\mathrm{Xu}, 2015)$. 
However, many issues about cloud manufacturing are still confusing and more attention should be paid to advance progress in this field (Chandrasekaran et al., 2013). The present work is a step forward in applying cloud computing concepts to the optimization of production planning.

\subsection{Production Planning and Control}

The development of cloud manufacturing needs to be synchronized with the development of enterprise manufacturing systems and manufacturing environment (Ma et al., 2013). It should support the overall management of processes, products, resources and information.

Production planning and control (PPC) is very critical for manufacturing execution. It includes tasks of job or task scheduling, inventory planning, loading production, process selection and planning, facility location, estimating quantity and costs of production, capacity planning, line planning, follow-up, and execution. In the context of cloud a manufacturing environment, PPC is even more difficult and complex. There are two main considerations:

(1) Temporality of delivery configuration - The cloud manufacturing mode is driven by the uncertainty of customer orders. When a customer order is received, participants in CM should quickly form a virtual enterprise based on the cloud service, and with the delivery of the product or service the virtual enterprise is dissolved. This feature of CM distinguishes it from traditional PPC (Ning et al., 2011). In order to respond to dynamic requests, the PPC must embed attributes adaptively so as to provide a reconfigurable interaction model (Caridi and Cavalieri, 2004).

(2) Networked manufacturing - A single process includes multiple participants (i.e. cloud services providers and users), distributed resources, and decentralized management. Therefore, multiple process plans should be defined for each supplier, and each sub-process plan needs to determine alternative operations and alternative machines (Um et al., 2014). Due to the different status (i.e., system configuration and customer demands) of each supplier, the quantifications and requirements are different (Caridi and Cavalieri, 2004). In order to monitor the distributed manufacturing processes and guarantee the quality of final delivered services, a set of Services Agreement Level (SLA) need to be defined in advance.

When discussing the PPC in CM environment, the topics consist of production planning, process management, and also supply chain optimization. The optimization of the supply chain includes every link in procurement, marketing, logistics, planning, and scheduling. The optimization involves collaborative project management and resource distribution and scheduling to improve resource utilization and efficiency. 


\subsection{Optimization in Cloud Manufacturing}

Cloud manufacturing approach can offer centralized optimization service for the production units. With the dynamic changing of manufacturing resource services, the quality of resource services and the requirements of enterprise users, there are many uncertain factors influencing the dynamic optimization of resource services, which make the manufacturing task impossible to be completed efficiently and with high-quality. Various optimization tasks can be conducted to solve dynamic problems by centralized cloud manufacturing services.

Production process optimization is one of the most widely investigated topics in the field of manufacturing (Chandrasekaran et al., 2013). Formally, the process of optimization in manufacturing engineering consists of the following processes: (i) defining variables, constraints, and objective function(s), (ii) solving the constrained problem of general mathematical form by using various types of algorithms and methods, and (iii) simulating the optimization algorithm and then deploying the algorithm in practical systems for application (Tao et al., 2015). Different types of optimization can be employed due to the different nature of the formulated manufacturing problems.

Tao et al. (2015) provide a comprehensive analysis of all kinds of manufacturing optimization problems and their general methods. It is shown that optimization can be applied almost everywhere. Currently, most existing studies focus on the optimization objectives in areas such as management of manufacturing process, design and analysis of product/element, and system management and control. The optimization problems include both single-objective and multi-objective ones (Tao et al., 2015). Multi-objective optimization refers to the optimization problem crossing different disciplines, and it is always very complicated. It includes different variables and parameters to solve one single optimization problem. However, the methods of onsite decision or multi-step optimization in collaborative manufacturing are inevitably not thorough enough. Therefore, multi-disciplinary optimization becomes a significant challenge and it is the most recent trend in the development of advanced manufacturing systems.

The dynamic changing of manufacturing requirements produces many uncertain factors. The adoption of cloud can bring a lot of benefits to manufacturing companies. In terms of cloud manufacturing, the optimizations can be discussed from two aspects: cloud resource optimization and manufacturing resource optimization. Cloud resources refer to technical infrastructure and on the other hand manufacturing resources mean the physical resources in manufacturing. Tharumarajah (2001) describes resource allocation problems as the embodiment of the choice of resources, performance, and constraints. Both types of optimizations in cloud manufacturing are discussed based on this principle.

The first utilization of cloud computing resources was their use in optimizing manufacturing resources (Laili et al., 2012). In cloud computing, there are different kinds of computing resources, such as cloud 
storage (Rimal et al., 2011) and transaction process (Zeng et al., 2009), and these resources can be virtualized and then applied to optimize the schedule of using these resources. Cloud systems can automatically control and optimize resource use by leveraging a metering capability at some level of abstraction that is appropriate to the type of service (e.g., storage, processing, bandwidth, and active user accounts) at the physical layer in computing. Resource usage can be monitored, controlled, and reported, providing transparency for both the provider and consumer of the utilized service (Mell and Grance, 2009).

The second type of optimization is the use of the cloud concept to obtain on-demand cloud resources to optimize the business processes. Cloud-based solutions enable better-integrated and more efficient business processes to improve the efficiency of operation. In cloud manufacturing, it is not only about providing computing resources, but also controlling a variety of other manufacturing resources and abilities directly for collaboration and sharing (Laili et al., 2012) through the whole manufacturing lifecycle. Therefore, the core focus of cloud manufacturing is to optimally use dispersed manufacturing resources in the prevailing trend to attain a low-carbon footprint in economic development (Ning et al., 2011).

In the cloud manufacturing research area, the most discussed issue is resource (service) optimization. Manufacturing resources refer to resources that are required during the product development life cycle (Xu, 2012). These manufacturing resources may take two forms: manufacturing physical resources and manufacturing capabilities. Manufacturing physical resources can exist in hardware or software form. The former includes equipment, computers, servers, raw materials, etc. The latter includes, for example, simulation software, analysis tools, 'know-how', data, standards, and employees. Some manufacturing capabilities are intangible and dynamic resources representing the capability of an organization undertaking a particular task with competence. These may include product design capability, simulation capability, experimentation, production capability, management capability, and maintenance capability $(\mathrm{Xu}, 2012)$. Therefore, the optimization problems in cloud manufacturing are optimizing the manufacturing resources, and matching these resources with specific capabilities.

In cloud manufacturing, the optimization process consists of some key elements: the users submit a computing (manufacturing) resource request, the cloud manufacturing system platform analyzes the mission, divides it into subtasks in accordance with the requirements from users, executes scheduling algorithms for mapping these requirements to available resources, allocates resources optimally, and sends a final solution back to the users (Laili et al., 2012). Compared with traditional manufacturing paradigms, the optimization complexity is increasing in cloud manufacturing because the requirements of supply chains are dynamic and the parameters changing as a manufacturing process proceeds. 


\section{Functional requirements for sheet metal processing}

Companies operating in sheet metal forming (SMF) are at the beginning stage of manufacturing for a broad spectrum of industries including automotive, aerospace, energy, domestic appliances, electric cabinets, elevator, and escalators. Production steps consist of units such as punching, shearing, laser cutting and sheet metal handling systems. SMF industries, in comparison with other discrete part manufacturing industries, are typically highly automated and flexible in production diversities.

\subsection{Decision problems}

Sheet metal processing has some special characteristics in terms of production planning and control. Many of the decisions are completed several times a day and analytic techniques such as mathematical optimization in nesting are widely used.

Traditionally, optimization tools have been used to solve the sheet nesting problem. For example, Nehal et al. (2012) proposed a genetic algorithm based system. Huang et al. (2009) presented optimal layout and path planning for flame cutting of sheet metal. Optimization has also been used in the sheet metal forming process (Gantar et al. 2002, Liu and Yang 2008, Wang et al. 2008, Wang and Xie 2005). However, there is still limited capability in shop floor applications of optimization methods, due to the complexity and volatility of different processes, and also because of the non-availability of required information (Chandrasekaran et al., 2013).

Managing tools and setups is also a typical complex problem in sheet-metal production. Giannakakis and Vosniakos (2008) introduced an expert system for making this decision. Marvizadeh and Choobineh (2013) introduced a similar process for punch presses. Akturka et al. (2007) and Daskin et al. (1990) have also introduced analytical approaches in the same domain.

The scheduling of production has been also studied. Some specific features could be non-identical machines and tools. Gurel and Akturk (2007) have considered the job allocation problem in nonidentical parallel machines. Hirvikorpi et al. (2008) introduced a scheduling system considering wearing tools and stochastic lifetimes. In CM environment, the decision making process for PPC is divided into different levels when the manufacturing become more and more distributed. As an effective solution, cloud computing infrastructure can be used to develop reliable predictive models and carry out the optimization in a cloud (Chandrasekaran et al., 2013).

\subsection{Business Requirements}

The motivation of this research is to demonstrate the realization of a cloud manufacturing environment which can transfer cloud-based solutions to the manufacturing domain, and make sure that 
manufacturers can benefit technically, and also conceptually. The goal is to combine various manufacturing resources and capabilities dynamically in such a way that customers can access them as if they were in a single facility. However, production planning and control and their optimization are the main focus of this research.

To have a better understanding of cloud-based production planning and control and its opportunities the requirements for a CM system were collected from SMF solution provider. Twelve related domain experts were interviewed twice during a specific time period. In the first round experts in different disciplines of the company were required to provide their technical opinions about the optimizations. After presentation of their points, face-to-face interviews were conducted and the requirements of each discipline were analyzed. Table 1 summarizes the key requirements which were used to develop a prototype $\mathrm{CM}$ environment. The main requested linkages included factory level control with connections to both steel sheet suppliers and customers placing orders for the production. The real-time visibility was requested within production line (RQ1) and in the supply chain to see the planned and actual progress of each work (RQ4). From a process view, the main connections were to design CAM (computer-aided manufacturing) activities. Design of a product is a main driver for task durations, tools and setups - for this reason CAM software packages need to be communicate directly with cloud based system (RQ2).

A common set of key performance indicators (KPIs) was requested for the entire supply chain (RQ3) as machines are providing this information for the production planning needs.

The primary requested functionality (RQ5) was to have an optimization based production planning system to combine line-level capacity, raw material usage, and various machine related setups. However, this system should be parameterized for different needs.

Status information for each work and events in different parts of the production process are centrally stored in the cloud system. This information should be available for change management and rescheduling considerations (RQ6). Planned and actual production plans should be compared as typically in low volume production, the predicted processing times may vary from actual and manual parts of the process such as tool changes, material feeding and operator confirmations may take more time than planned. In order to improve the understanding of variability, actual processing times were requested to be stored for learning and development purposes (RQ7).

Table 1. Requirements collected for cloud-based product planning and control. 


\begin{tabular}{l|ll|} 
RQ1 & $\begin{array}{l}\text { Overall line level production planning and control combining all } \\
\text { machines and phases }\end{array}$ & 1 \\
RQ2 & CAM and dynamic nesting connected to PPC & 2 \\
RQ3 & Real-time key performance indicators & 2 \\
RQ4 & $\begin{array}{l}\text { Access for customers and suppliers to see work and material tracking } \\
\text { information }\end{array}$ & 2 \\
RQ5 & Dynamic multi-objective optimization for scheduling & 1 \\
RQ6 & Event management for re-planning of the supply chain & 3 \\
RQ7 & Actual processing times feedback for production planning & 3
\end{tabular}

\subsection{Functional Requirements}

Based on the business requirements, more specific functional requirements are defined and developed. Figure 1 shows a general reference model of CM for SMF industries. This architecture was based on the pertinent articles that were reviewed and both the Purdue Reference Model for Control Hierarchy and ISA-95. The Purdue Reference Model of Control Hierarchy is a commonly used architecture model to define manufacturing operations management. It breaks the production lifecycle into different phases. Whether they serve as part of continuous production, job production or batch production, automation and information systems fall under this model (Adiseshan, N.D). ISA-95 is the international standard for the integration of enterprise and control systems. ISA-95 consists of models and terminology. These can be used to determine which information has to be exchanged between systems for sales, finance and logistics and systems for production, maintenance and quality. This information is structured in Unified Modeling Language (UML) models, which are the basis for the development of standard interfaces between ERP and MES (Manufacturing Execution Systems) (ISA-95, 2014).

Interoperability of various IT systems is an important topic in cloud manufacturing. Cuesta et al. (1998) introduced a concept integrating CAD and CAM systems for sheet-metal cutting. Rao et al. (2006) introduced an integration system for sheet-metal job shops. The integration of system design and closing the gap between design and production has potential. Alva and Gupta (2001) presented an automated design for sheet metal bending operation.

The model in Figure 1, maps the plant-wide information flow from the sensors to the boardroom in four distinct levels, from the most fundamental to the most advanced.

- Level 1 is for physical devices process, which includes an individual machine or machine tool as the smallest unit of the manufacturing system. This supporting equipment includes intelligent transportation, robots, and also laser, cutting, shearing and bending machines.

- Level 2 represents site manufacturing operations and controls. Different kinds of controller are used for automation of the diverse machines and devices in Level 1. 
- Level 3 addresses plant-wide applications, including Manufacturing Execution Systems (MES), asset management and Material Requirements Planning (MRP) for production planning, scheduling and inventory control.

- Level 4 is the enterprise level. It consists of business systems and quality databases. It can integrate multiple Level 3 systems and ensure cross plant boundary cooperation.

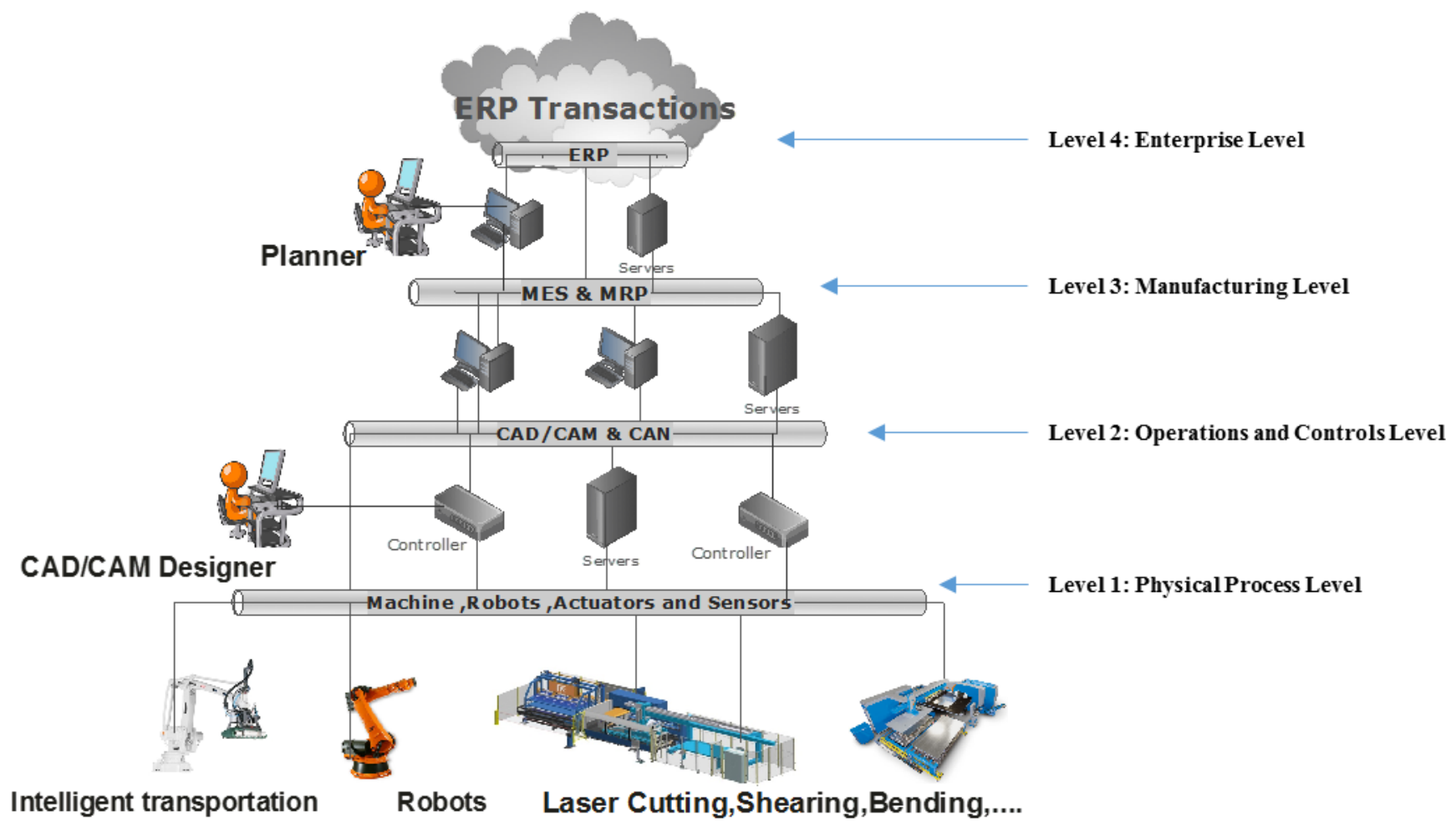

Figure 1. Integrated optimization platform in sheet metal processing.

Existing advanced planning and scheduling systems provide many features requested. However, there are some features of a cloud-based system for production planning and control, which differ from traditional stand-alone software solutions:

(1) Emphasis on supply chain integration for customers and suppliers by providing real-time access

(2) Possibility to conduct planning activities centrally for multiple factories and supply chain

(3) Integration of CAM processing of laser cutting, punching, bending, and nesting into integrated product data model

(4) Real-time event handling and key performance indicators connected to planned and actual production schedules 


\subsection{Cloud Manufacturing in the Sheet Metal Industry}

A cloud manufacturing approach involves collaboration across the whole manufacturing process, and the cloud-based PPC and optimization problem in the sheet industry must encompass every link in the manufacturing process, as presented in the following sections.

\subsubsection{Product design process}

The manufacturing design process in SMF includes the use of various CAM systems. Typically, geometric design is combined with material information and decisions related to sheet type, machine, tool, and work sequence are made. In the case of 2D objects, the selection is made between using shearing and laser cutting. For 3D parts, CAM instruction is needed for bending machines as well. For manufacturing planning, these decisions have a great impact. Sheet size can affect nesting efficiency and tool selections may have consequences in terms of the frequency of setups. Also nesting principles vary in the case of push type make-to-stock production or high mix make-to-order type of production. Having idle capacity versus wasting raw material due to lower utilization is the decision to be made. When several machines have varying setups and layout is constrained by fixed conveyors or WMS (Warehouse Management System), balancing the line in various cases becomes an important task. Much of this is determined in the CAM and design process.

As an example, manual adjustment of the sheet metal size from available sizes of sheet metal influences the utilization rate of the different nesting layouts considerably. This highlights the point that the system needs fundamental reconfiguration in a few aspects of nesting algorithms with respect to the available amount of raw materials. The possible problem is that the optimization is the definition of local optimum point for each job even though there are possibilities to search for global optimum answers. The flexibility and interconnections of variables in different manufacturing processes should be taken into account in supply chain level optimization. The variables include speed for the machine actions, speed of tool changing, maintainability, durability and set up times. Figure 2 illustrates an integration of CAM processes into one single data element shared by CAM designers to cover all machine types and full integration into the PPC system for dynamic nesting. 


\section{Towards Integrated $2 \mathrm{~d}$ and $3 \mathrm{~d}$ CAM process}

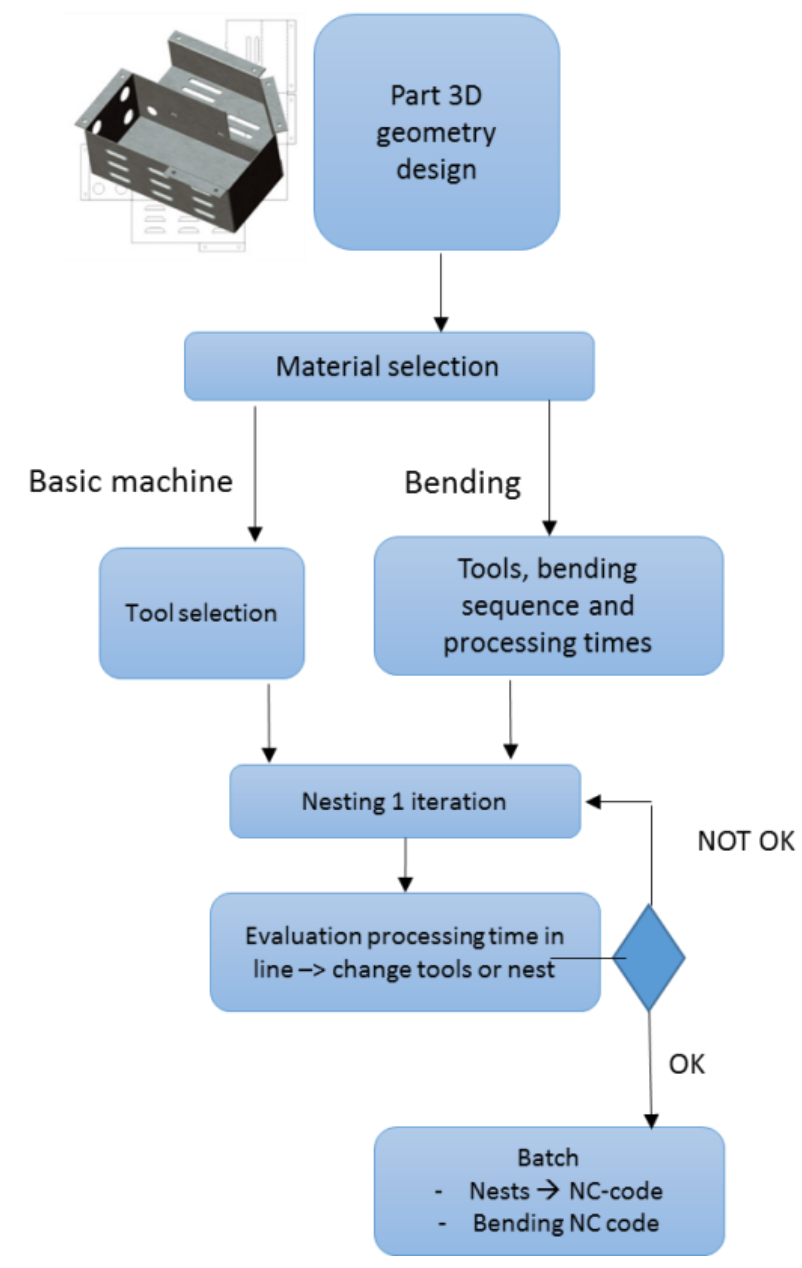

Figure 2. Integration of CAM processes.

\subsubsection{Production Planning - Manufacturing Execution System}

With regard to cloud-based optimization, production planning and especially scheduling has the highest potential for optimization. It ensures that customer orders can be fulfilled as requested. According to expert interviews, many SMF companies typically manage the capacity of different machines and machine sequencing using operators' experience. This means that many smaller SMF companies do not use available production planning techniques fully, but instead use first come first serve (FCFS) type of policies with rush orders.

Typically, MES is used to support the manufacturing facility and take care of the communication channel of shop floor and administration, and interface with the ERP system. It is very important that the two systems are linked so that the shop floor will know what is happening at the business level and vice versa. Such two way communication will result in the optimization of activities throughout all 
aspects of the manufacturing process. MES mainly covers resource allocation, operation scheduling and production planning. Typically, the production process for each product can be described as a working flow in the plant. The sequence of each flow is controlled by MES. Several robust algorithms for scheduling, and sequencing are available. A variety of sensor data from the machines, for example job completion, tool wearing and energy consumption are employed in manufacturing devices to collect real-time status information. Pre-emptive and closed feedback loop planning can be implemented by combining real-time sensor information with production planning zones (Figure 3).

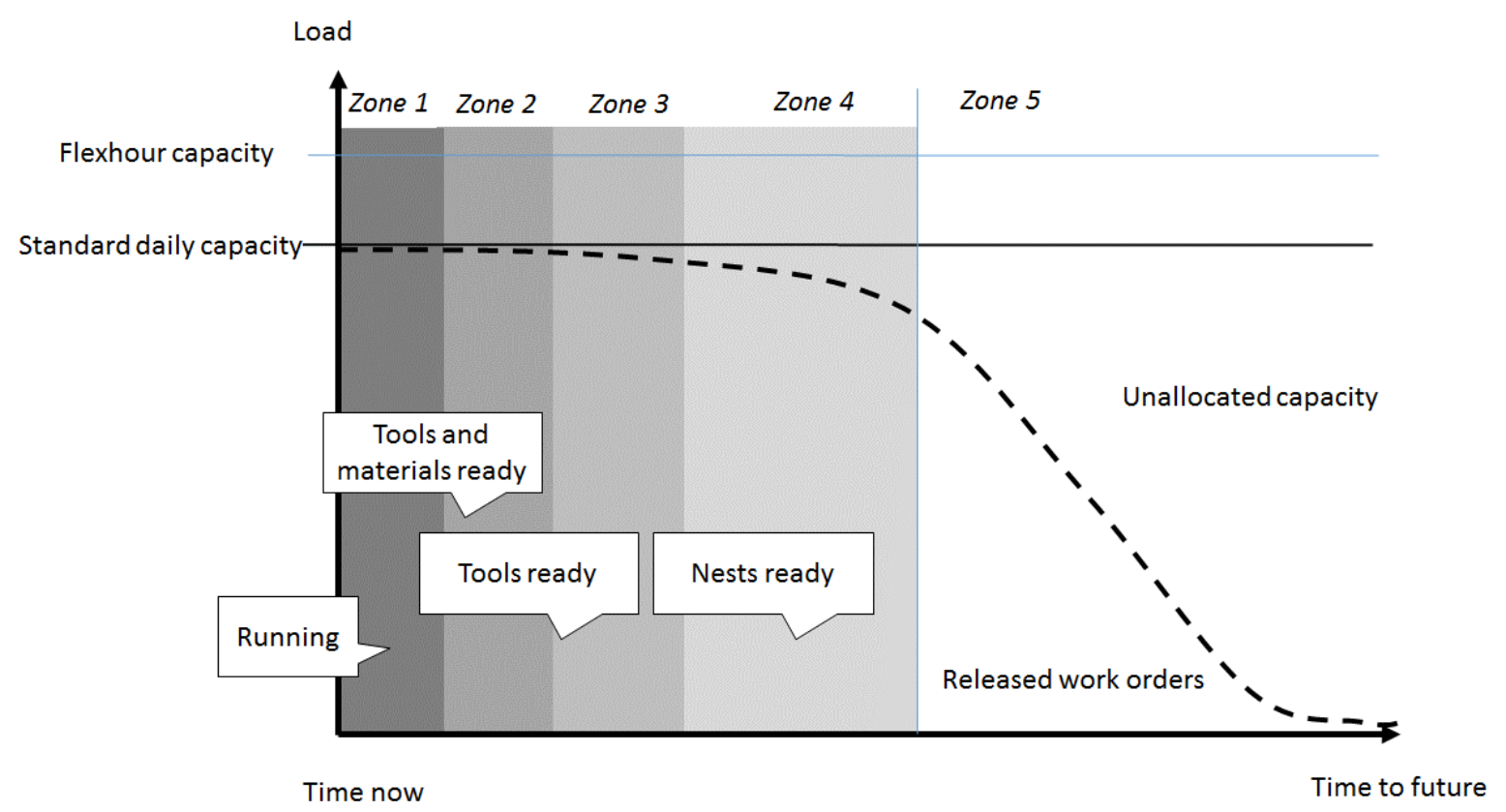

Figure 3. Production planning time horizon and dynamic planning.

A centralized service for production planning prototype was implemented to test the concept. Figure 4 illustrates a work center production schedule which is generated by the centralized scheduling engine offering production planning as a service. This functionality is fulfilled by changing parameters and adding desirable properties, and then setting up manufacturing job requirements and certain criteria, such as running sequentially or in parallel. A metaheuristic system changes the order sequences by minimizing the total processing time. 


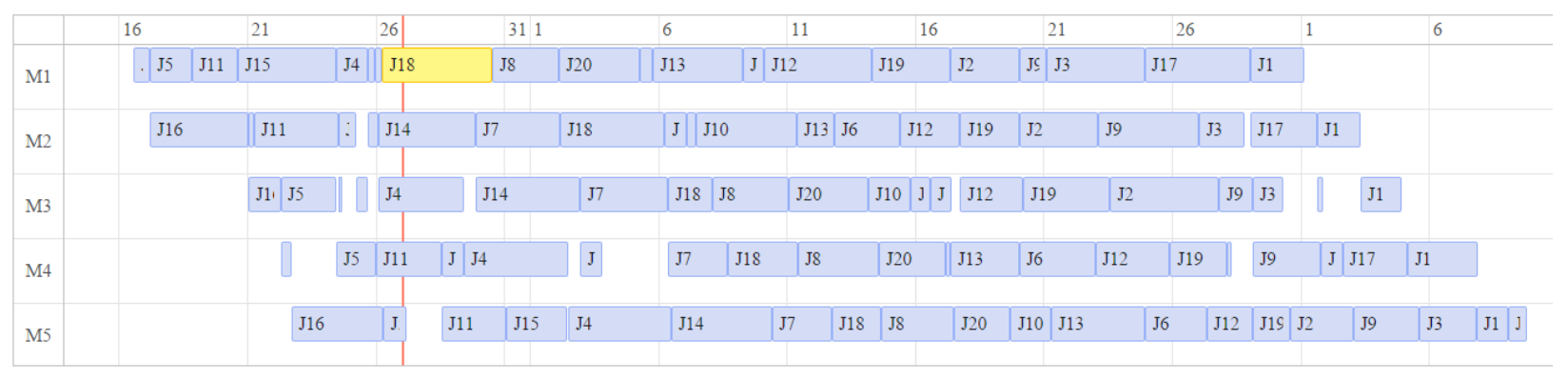

\section{Production planning objectives \\ MIN total processing time}

- Tool setup time

- Material setup time

- Cassette change setup time

- Scrap change setup time

- Planned maintenance time

Subject to:

- Due dates

- Machine capacity

Figure 4. Screenshot of the developed cloud-based scheduling service result and its objective.

\subsubsection{Machine control}

\subsubsection{Shearing, punching and laser cutting}

The main objective of using the basic machine is the maximization of utilization rate of sheet metal, and the constraints are the product shapes that need to be fulfilled and the size of the available sheets. Therefore, using a cloud-based solution can enable the testing of different algorithms for nesting and computational functionalities, supporting the parallel data mining, and maximizing the performance of analytics. These features are different to traditional computing environment.

In practice, the optimization problem can be formulated as follows: maximizing capacity utilization by re-sequencing orders, subject to external events and previous machinery on the line.

The optimal solution should be calculated and updated continuously subject to any changes in the production plan or execution sequence. In practice, this refers to the requirements of systems as follows:

- Pre-emptive operations, planning, and updating production schedule in real-time based on experience.

- Developing 'plan-B scenarios' in real-time and adjusting production plan quickly 
- Integrating communication between each machine in the line to understand what might happen next.

\subsubsection{Robotics}

Robots are typically working as slaves in these types of production lines. The optimization of this discipline mostly relies on the movement and responsibility of the robots. The result of the interview indicates that one of the most important issues that need to be taken into account is the speed of the robot arms in movements and optimized timing. Today, movements for robots are programmed at the maximum speed of the robots without real-time consideration of subsequent movements. The basic movements of the arms have to be optimized not only based on the stacking area optimizations but also based on the minimum cost (including maintenance, etc.) of the movement for the production lines.

The robot movements in the execution could be optimized in terms of the timing of the robotic arm movements with consideration of the concept of time in different layers.

By using interoperability between machines in production line, the robot movements may have different modes: full speed, high-reliability night-shift mode, communication with robot and other machines for line level availability. This information could be used for pre-emptive planning and automatic routing changes in the case of multi-processors.

\subsubsection{Bender lines}

The timing of bending and other 3D operations plays a significant role in the flow of work in SMF. As the throughput rate of bending normally is lower than the other manufacturing units, optimization needs to rely on the timing and scheduling of the machines.

The role of bending time in production scheduling, possible buffer allocations and job sequencing is a promising field of optimizations for this section:

- Output sequence of jobs

- First stacking time measurement: Re-nesting parts on sheets

- Multiple parts into stacking

- New stacking buffering: Temporary to the sorting area.

\section{Architecture for cloud manufacturing}

\subsection{Conceptual model of optimization}

Based on the requirements and possibilities of cloud manufacturing, a prototype system for cloud-based production planning and control of SMF production was created. Figure 5 demonstrates the process of providing optimization services based on customers' requirements. According to the principle of 
manufacturing resource transfer, service-oriented cloud manufacturing includes three main parts: manufacturing resources and capabilities as input, resources operating platform with multi-optimization levels, and the output of manufacturing services based on demand.

The manufacturing resources and capabilities which are provided by a cloud service provider are virtualized in the cloud manufacturing platform, and they are available for retrieval by cloud service users. The capabilities are the ability to integrate resources and disseminate results when a task is completed. Capabilities across the whole manufacturing process are always bundled with particular resources. In other words, resources are the basis for achieving capabilities. In order to optimize the manufacturing resources and capabilities, the optimization issues are classified into different optimization levels. The multi-objective optimization levels provide support for achieving the ondemand use and circulation of manufacturing resources based on distributed customers' requirements. The following sections will present optimization possibilities in different levels.

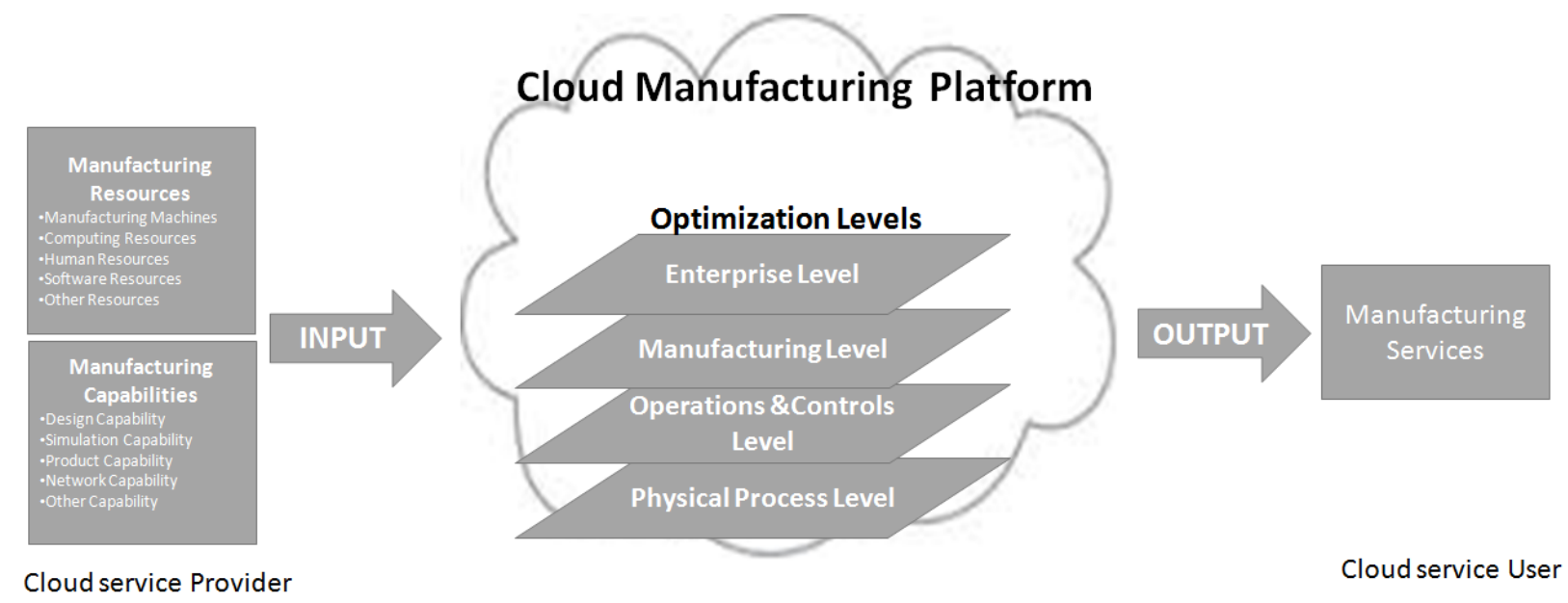

Figure 5. Conceptual model of optimization in cloud-based PPC.

\subsection{Optimization Services in Cloud Manufacturing}

Cloud manufacturing concept presented in this paper is a centralized platform supporting domain specific optimization tasks. Comparing this approach to agent based systems or distributed scheduling, the main emphasis is on shared real-time view and possibility to utilize the information rather than interaction between different decision making entities. Cloud manufacturing approach enables certain technical possibilities, but does not solve all behavior related challenges as information asymmetry and different power constellations which take place in supply chains. The extent of shared information must be agreed between partners. Additionally, the scheduling objective function can be adjusted and parameterized. This means that each participant may include those parameters, which are important for their business. For example, a company producing high volume HVAC (heating, ventilating, and air 
conditioning) components can appreciate fixed daily schedules aiming low raw material waste rate synchronized with assembly operations in downstream. On the other hand, a contract manufacturing company can charge more for fast delivery and raw material utilization is not that important in highmix low-volume (HMLV) production.

Parameterization of production planning and scheduling is a complex process and it depends on company strategic objectives. There are different level optimization tasks in terms of temporality of the decisions and some of them may be contradicting with each other. Table 2 illustrates possible layers and examples of objectives at each level. The proposed layers indicate the hierarchical structure of an integrated platform of optimizations particular to this type of manufacturing. Based on the reference architecture proposed in the research motivation, a generic multi-objective optimization system has been built by using genetic algorithms (GA). Each domain can use the centralized system for proposing solutions. Templates for optimization problem formulation may be provided in the cloud system. However, the actual parameterization of objectives functions for each decision layer remains as a company level decision.

Table 2. Optimization objectives related to SMF in different layers.

\begin{tabular}{|c|c|c|c|c|}
\hline Layer & Frequency & & $\begin{array}{l}\text { Optimization } \\
\text { objectives }\end{array}$ & Optimization targets \\
\hline Enterprise layer & $\begin{array}{l}\text { Strategic } \\
\text { Annual }\end{array}$ & & $\begin{array}{l}\text { Maximize return on } \\
\text { investment (ROI) } \\
\text { Maximize profit }\end{array}$ & $\begin{array}{l}\text { Ensure current proposed product type, } \\
\text { product mix and product volume can } \\
\text { maximize the profit. }\end{array}$ \\
\hline $\begin{array}{l}\text { Manufacturing } \\
\text { layer }\end{array}$ & $\begin{array}{l}\text { Tactical } \\
\text { Quarterly }\end{array}$ & & $\begin{array}{l}\text { Minimize lead time } \\
\text { Minimize total } \\
\text { proceeding time }\end{array}$ & $\begin{array}{l}\text { Management of the manufacturing } \\
\text { process. It is a central line for the } \\
\text { whole life cycle of manufacturing. }\end{array}$ \\
\hline $\begin{array}{l}\text { Operations and } \\
\text { control layer }\end{array}$ & $\begin{array}{l}\text { Operational } \\
\text { production }\end{array}$ & - & $\begin{array}{l}\text { Maximize the } \\
\text { performance - lead- } \\
\text { time, capacity } \\
\text { utilization, material } \\
\text { utilization }\end{array}$ & $\begin{array}{l}\text { Guarantee the efficient operation of the } \\
\text { whole manufacturing system. } \\
\text { Improve the communication with } \\
\text { machines }\end{array}$ \\
\hline $\begin{array}{l}\text { Physical process } \\
\text { layer }\end{array}$ & $\begin{array}{l}\text { Operational } \\
\text { design } \\
\text { Daily }\end{array}$ & & $\begin{array}{l}\text { Maximize the machine } \\
\text { utilization } \\
\text { Minimize the working } \\
\text { time } \\
\text { Maximize the material } \\
\text { utilization } \\
\text { Minimize the material } \\
\text { cost }\end{array}$ & $\begin{array}{l}\text { This contains the structure design and } \\
\text { modeling and finite element analysis } \\
\text { of product. It is the core object of } \\
\text { manufacturing. Optimization in this } \\
\text { category is also known as structure } \\
\text { optimization. }\end{array}$ \\
\hline
\end{tabular}


Optimizations in each layer of operation have to be done separately, but the data and results must be shared among the all the decision levels as shown in Figure 1 (Section 3.2). In general, a supervisory level of Enterprise Resource Planning (ERP) acts as a gateway of data and information for a SMF. This layer of optimization (automation) also coordinates possible intra-enterprises data transactions and prepares the data for other levels for their real-time optimization.

\subsection{Technical implementation}

In order to present the technical implementation considerations of this platform, a demonstration system or a prototype was built. Each system has local level control and work queue. Machines receive instructions from the cloud-based production plan and requests from production control. Then the machines feed in information on actual progress vs. planned activities (See Figure 6). The actual progress information is retrieved from a network of sensors. To achieve effective management of the sensor data described above, the cloud manufacturing platform needs to offer the following two primary functions: (1) the effective distributed storage of sensor data, and (2) the efficient parallel search, filter, and statistics of sensor data (Bao et al., 2012). The cloud computing model is used to get all the local factory-related data and provide optimized results to improve machine performance.

Cloud computing is used to provide on-demand service of computing facilities and database. The machining optimization can suggest an initial setting and accept feedback from the real machining process. 


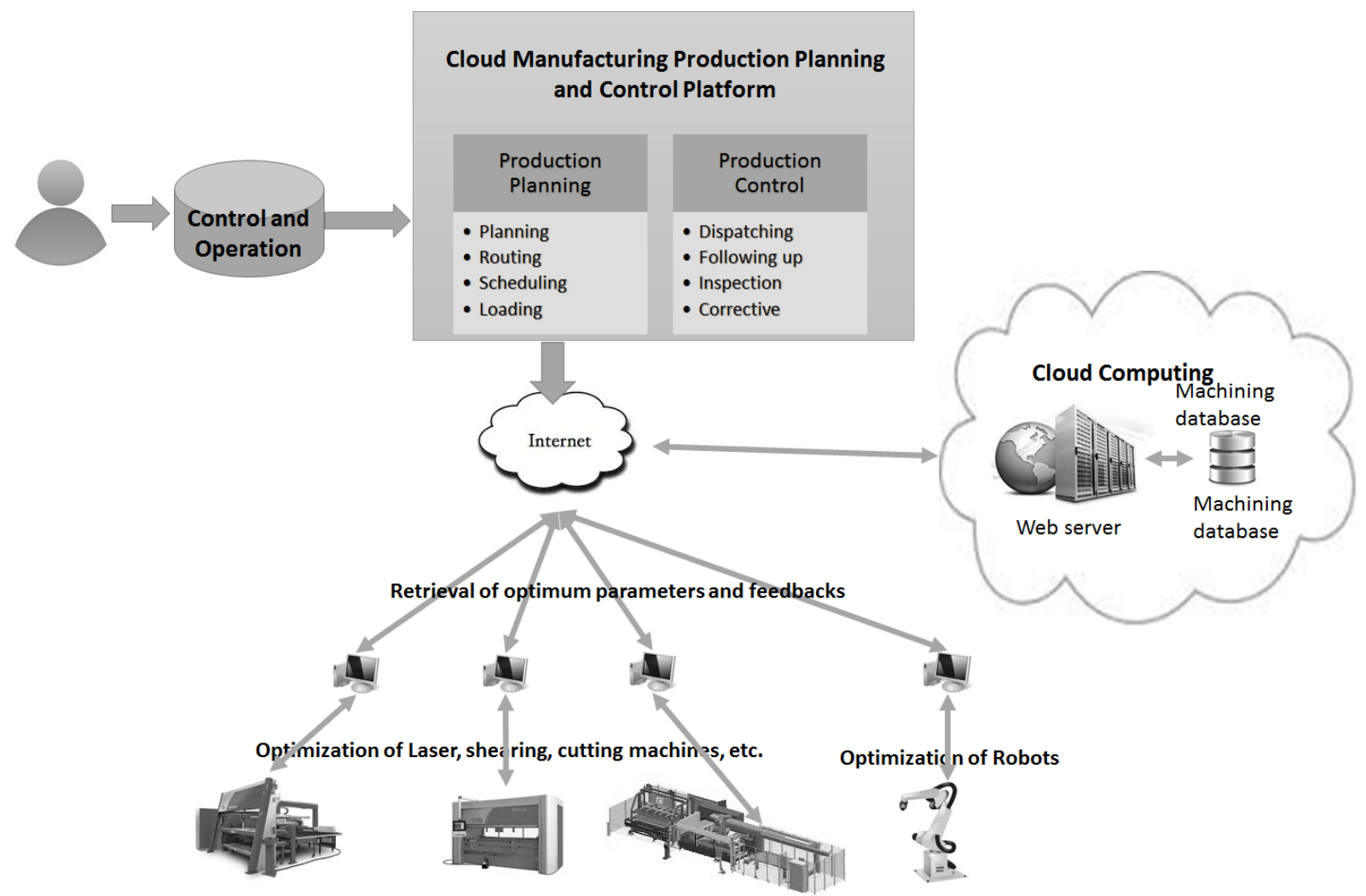

Figure 6. Structure of cloud computing-based optimization system.

A holistic view of the key aspects of conceptual system structure is depicted in Figure 7. It allows a wider perspective of implementing the cloud-based PPC into the cloud manufacturing concept. It describes the cloud manufacturing as a whole manufacturing process. The customers and suppliers have a different API to plug into this cloud manufacturing platform. Several cloud services are also integrated into this platform with the aim of optimizing production processes, factory planning, and design. Centralized computing power can be used to solve production planning, allocation scheduling, tooling and setup decisions. Algorithms may be updated, and all the machines may obtain the benefit of the latest versions as these are offered as cloud services. 


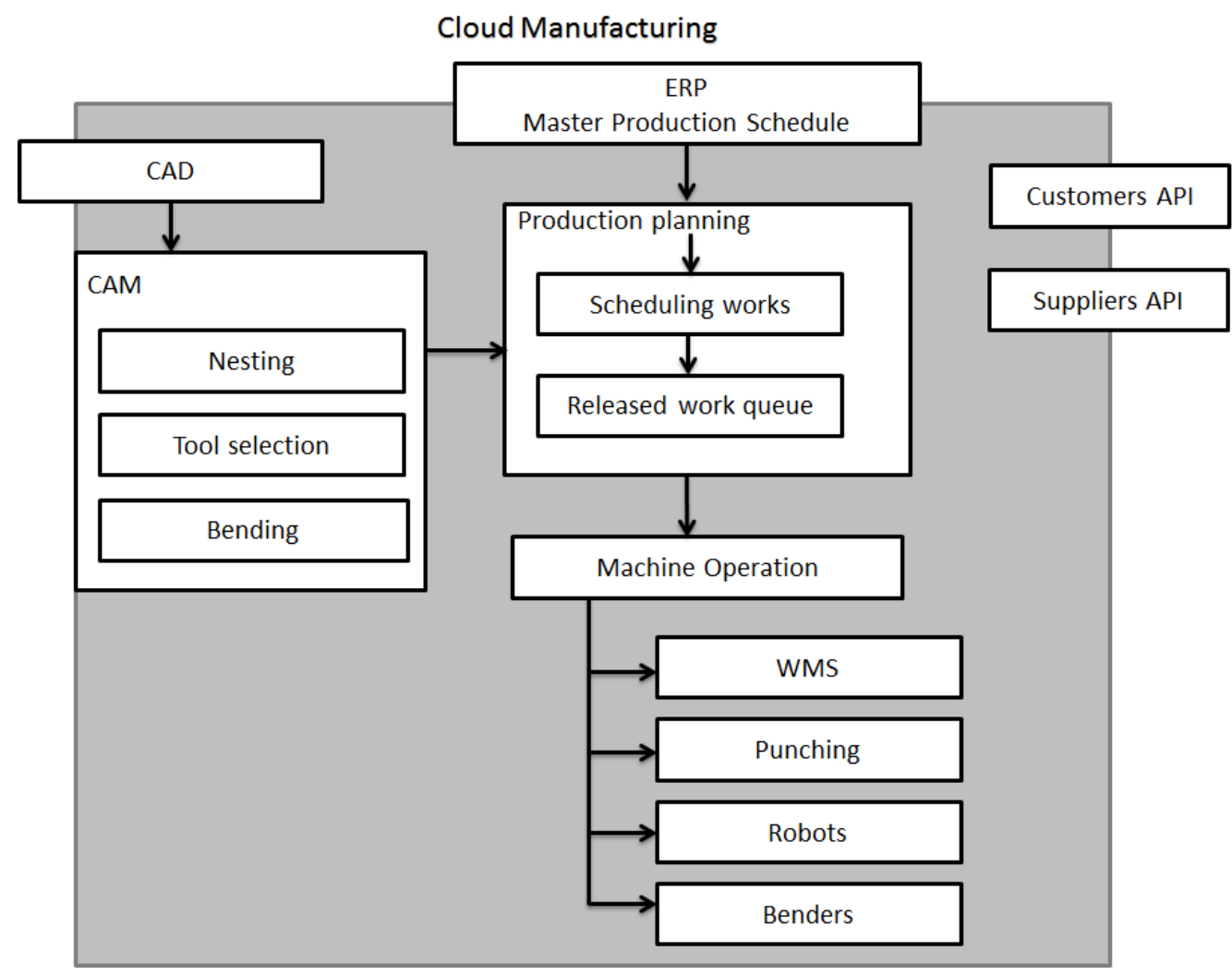

Figure 7: Cloud-based PPC structure in the scope of sheet metal processing.

Based on the collected requirements and specifications, a common data model is developed for integrated production control system. The main entities and their relationships are described at an abstract level in Figure 8. All machines and planning tools need to share the same structured data in both planning and execution phases.

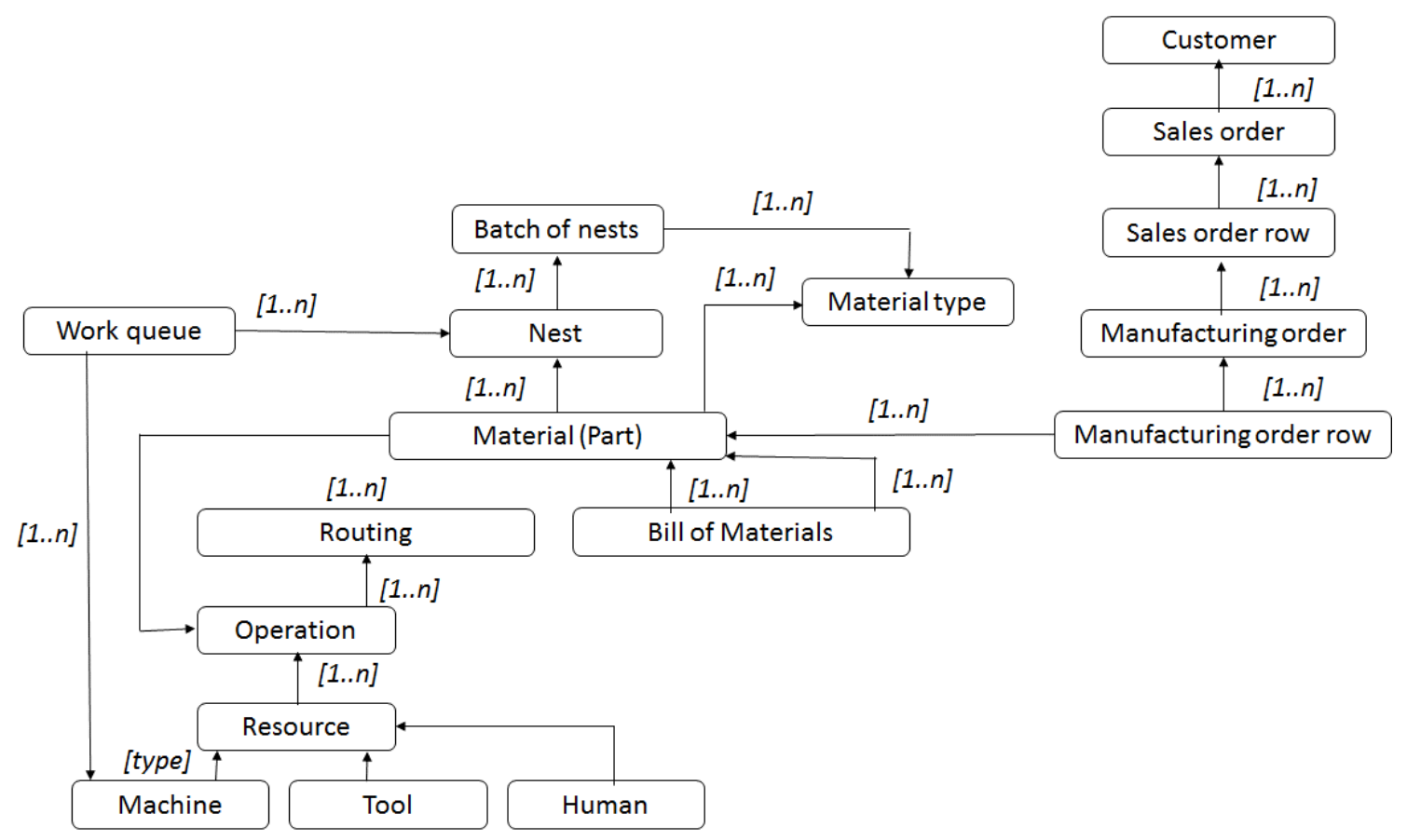


Figure 8. Entities related to cloud-based production planning and control.

The prototype system was developed and tested with actual data collected from an existing production line. The validation of the scheduling system was conducted only in simulation, not in a real production environment. Some observations from piloting showed that production lines may be complex and consisting machines of different generations and types. Flexibility of configuration and adjusting the platform for each situation is an important property. Ability to adjust is related to communication, line configuration and company specific optimization objectives. Testing showed the importance of ability to operate easily in different and changing environment.

\section{Conclusions}

A new smart manufacturing model - cloud manufacturing has been proposed to fulfill the requirements of networked and dispersed production in sheet metal manufacturing. The cloud provides a collaborative environment that can give people who manage a sheet metal manufacturing (SMF) agility, more transparency, and empowerment through more effective collaboration.

In this paper, the functions and requirements of a cloud-based production planning control and continuous operational optimization are presented in the sheet metal manufacturing context. With the aid of the concepts, the technical conceptual structure and data modeling were established when implementing the prototype system. Based on the initial piloting test, the strategy presented in this research could help manufacturers to build capacity within their organizations, and to securely and reliably collaborate with other manufacturers, and stimulate the growth of the cloud for the next wave of business productivity and optimization.

It is very important for both academics and industries to notice that the application of cloud manufacturing will be a long-term process, and it will gradually develop in many factories. In order to be successful, factories should have a good foundation for the internal integration of information and processes. Therefore, there is a relatively high entrance standard to implement cloud manufacturing for a majority of manufacturing companies. For a sheet metal manufacturing environment, a vision of plugand-play supply chain requires integrated information management and process management. The realtime scheduling and modular approach will be developed to enhance the flexibility of the system further. A centralized cloud-based system gives opportunities to accommodate different algorithms and try to improve or integrate cooperation between different algorithms. 
The future development of cloud manufacturing will face many challenges in key technologies. Security is the major challenge in any networked computer system. Because cloud manufacturing is highly reliant on networks, it also involves the security issue. The greatest challenge facing cloud manufacturing is maintaining internal security. Maintaining security and protecting data in cloud manufacturing are both important for two reasons: (1) data often represents a large amount of money due to labor intensive tasks, and(2) data often represents knowledge and provides companies with a competitive edge. Based on the experiences from this study, it is believed that further research into cloud manufacturing will accelerate the development of an intelligent, networked, service-oriented, digitalized manufacturing industry.

\section{References}

Adiseshan, B., N.D.. Manufacturing in the cloud: Improved productivity and cost savings are on the horizon. White paper by inKumo, Inc.

Akturk, M. S., Ghosh, J. B., and Kayan, R. K., 2007. Scheduling with tool changes to minimize total completion time under controllable machining conditions. Computers \& Operations Research, 34(7), 2130-2146.

Alva, U., and Gupta, S. K., 2001. Automated design of sheet metal punches for bending multiple parts in a single setup. Robotics and Computer-Integrated Manufacturing, 17(1), 33-47.

Bao, Y., Ren, L., Zhang, L., Zhang, X., and Luo, Y., 2012. Massive sensor data management framework in cloud manufacturing based on Hadoop. IEEE International Conference on Industrial Informatics (INDIN), 2012 10th IEEE, 397-401.

Caridi, M., and Cavalieri, S., 2004. Multi-agent systems in production planning and control: An overview. Production Planning \& Control, 15(2), 106-118.

Chandrasekaran, M., Muralidhar, M., and Dixit, U. S., 2013. Online optimization of multipass machining based on cloud computing. The International Journal of Advanced Manufacturing Technology, 1-12.

Cheng, Y., Tao, F., Zhang, L., Zhang, X., Xi, G. H., and Zhao, D., 2010. Study on the utility model and utility equilibrium of resource service transaction in cloud manufacturing. In Industrial Engineering and Engineering Management (IEEM), 2010 IEEE International Conference on 2298-2302. IEEE.

Cisco, 2012. Cisco CloudVerse for Manufacturing. Cloud for Manufacturing at a Glance - Cisco. http://www.cisco.com/web/strategy/docs/manufacturing/mfg_cloudvers_aag.pdf 
Cuesta, E., Rico, J. C., Mateos, S., and Suarez, C. M., 1998. Times and costs analysis for sheet-metal cutting processes in an integrated CAD/CAM system, International Journal of Production Research, 36(6), 1733-1747.

Daskin, M., Jones, P. C., and Lowe, T. J., 1990. Rationalizing tool selection in a flexible manufacturing system for sheet-metal products. Operations Research, 38(6), 1104-1115.

Fatahi Valilai, O., and Houshmand, M., 2014. A platform for optimisation in distributed manufacturing enterprises based on cloud manufacturing paradigm. International Journal of Computer Integrated Manufacturing, 27(11), 1031-1054.

Ford, S. J., Rauschecker, U., and Athanassopoulou, N. A., 2012. System-of-system Approaches and Challenges for Multi-Site Manufacturing. 7th International Conference on System of Systems Engineering, Genoa, Italy-16-19 July 2012.

Frayret, J. M., D'Amours, S., and Montreuil, B., 2004. Coordination and control in distributed and agent-based manufacturing systems. Production Planning \& Control, 15(1), 42-54.

Gantar, G., Pepelnjak, T., and Kuzman, K., 2002. Optimization of sheet metal forming processes by the use of numerical simulations. Journal of Materials Processing Technology, 130, 54-59.

Giannakakis, T., and Vosniakos, G.C., 2008. Sheet metal cutting and piercing operations planning and tools configuration by an expert system. International Journal of Advance Manufacturing Technology, 36, 658-670.

Giriraj, M., and Muthu, S., 2013. A cloud computing methodology for industrial automation and manufacturing execution system. Journal of Theoretical \& Applied Information Technology, 52(3), 301-307.

Gurel, S., and Akturk, M. S., 2007. Considering manufacturing cost and scheduling performance on a CNC turning machine. EuropeanJournal of Operational Research, 177(1), 325-343.

He, W., and Xu, L., 2015. A state-of-the-art survey of cloud manufacturing. International Journal of Computer Integrated Manufacturing, 28(3), 239-250.

Hirvikorpi, M., Knuutila, T., Leipälä, T., and Nevalainen, O. S., 2007. Job scheduling and management of wearing tools with stochastic tool lifetimes. International Journal of Flexible Manufacturing Systems, 19(4), 443-462.

Huang, B., Li, C., Yin, C., and Zhao, X., 2013. Cloud manufacturing service platform for small-and medium-sized enterprises. The International Journal of Advanced Manufacturing Technology, 1-12. 
Huang, X., Xi, F., Li, J., and Zhong, Z., 2009. Optimal layout and path planning for flame cutting of sheet metals. International Journal of Computer Integrated Manufacturing, 22(1), 30-41.

Jiang, Y. X., Zhang, Y., and Ma, J. W., 2013. Research on virtualization of manufacturing resources. 2013 International Conference on Measurement, Information and Control (ICMIC), 2, 1060 1064.

Laili, Y., Tao, F., Zhang, L., and Sarker, B. R., 2012. A study of optimal allocation of computing resources in cloud manufacturing systems. The International Journal of Advanced Manufacturing Technology, 63(5-8), 671-690.

Li, B., Zhang, L. and Chai, X., 2010. Introduction to Cloud Manufacturing. ZTE Communications, $8(4), 6-9$.

Li, C., Hu, C., Wang, Y., and Zhu, P., 2011. Research of cloud manufacturing and resource encapsulation technology. Applied Mechanics and Materials, 58, 562-566.

Li, C., Yang, P., Shang, Y., Hu, C., and Zhu, P., 2012. Research on cloud manufacturing resource scheduling and performance analysis. Advanced Science Letters, 12(1), 240-243.

Liu, N., Li, X., and Wang, Q., 2011. A resource \& capability virtualization method for cloud manufacturing systems. 2011 IEEE International Conference on In Systems, Man, and Cybernetics (SMC), (1003-1008).

Liu, W., and Yang, Y., 2008. Multi-objective optimization of sheet metal forming process using pareto-based genetic algorithm. Journal of Materials Processing Technology, 208(1), 499-506.

Luo, Y. L., Zhang, L., He, D. J., Tao, F., Ren, L. and Tao, F., 2011. Study on multi-view model for cloud manufacturing. Advanced Materials Research, 201, 685-688.

Ma, P., Bao, W. X., Han, Q., and Zhang, X. W., 2013. Application of cloud manufacturing based on the principle of process-aware information system. 1st International Workshop on Cloud Computing and Information Security. 2013, November. Atlantis Press.

Marvizadeh, S. Z., and Choobineh, F. F., 2013. Reducing the number of setups for CNC punch presses. Omega, 41(2), 226-235.

Meier, M., Seidelmann, J., and Mezgár, I., 2010. ManuCloud: The Next-Generation Manufacturing as a Service Environment. ERCIM News, (83), 33-34.

Mell, P., and Grance, T., 2009. The NIST definition of cloud computing. National Institute of Standards and Technology, 53(6), 50.

Monostori, L., Váncza, J., and Kumara, S. R., 2006. Agent-based systems for manufacturing. CIRP Annals-Manufacturing Technology, 55(2), 697-720. 
Nehal, I.J., Avadhoot, R., and Ashish M. D., 2012. Nesting algorithms for placement of regular \& irregular shaped parts. International Journal of Engineering Research \& Technology, 1(5), 1-6.

Ning, F., Zhou, W., Zhang, F., Yin, Q., and Ni, X., 2011. The architecture of cloud manufacturing and its key technologies research. 2011 IEEE International Conference on In Cloud Computing and Intelligence Systems (CCIS), 259-263.

Parunak, H.V.D., Baker, A.D., and Clark, S.J., 1997. The AARIA agent architecture: An example of requirements-driven agent-based system design. Agents, 482-483.

Rao, Y., Huang, G., Li, P., Shao, X., and Yu, D., 2007. An integrated manufacturing information system for mass sheet metal cutting. The International Journal of Advanced Manufacturing Technology, 33(5-6), 436-448.

Rimal, B. P., Jukan, A., Katsaros, D., and Goeleven, Y., 2011. Architectural requirements for cloud computing systems: an enterprise cloud approach. Journal of Grid Computing, 9(1), 3-26.

Ripamonti, L. A., and Peraboni, C. A., 2010. Managing the design - manufacturing interface in virtual enterprises through multi-user virtual environments: A perspective approach. International Journal of Computer Integrated Manufacturing, 23(8-9), 758-776.

Shaw, M. J., 1988. Dynamic scheduling in cellular manufacturing systems: a framework for networked decision making. Journal of Manufacturing Systems, 7(2), 83-94.

Sikora, R., and Shaw, M. J., 1997. Coordination mechanisms for multi-agent manufacturing systems: applications to integrated manufacturing scheduling. Engineering Management, IEEE Transactions on, 44(2), 175-187.

Smith, R. G., and Davis, R., 1981. Frameworks for cooperation in distributed problem solving. Systems, Man and Cybernetics, IEEE Transactions on, 11(1), 61-70.

Tao, F., Laili, Y., and Zhang, L., 2015. Recent advances of intelligent optimization algorithm in manufacturing. Configurable Intelligent Optimization Algorithm, 35-80.

Tao, F., Zhang, L., Venkatesh, V. C., Luo, Y., and Cheng, Y., 2011. Cloud manufacturing: a computing and service-oriented manufacturing model. Proceedings of the Institution of Mechanical Engineers, Part B: Journal of Engineering Manufacture, 225(10), 1969-1976.

Tharumarajah, A., 2001. Survey of resource allocation methods for distributed manufacturing systems. Production Planning \&Control, 12(1), 58-68.

Um, J., Choi, Y. C., and Stroud, I., 2014. Factory planning system considering energy-efficient rocess under cloud manufacturing. Procedia CIRP, 17, 553-558. 
Wang, G. G., and Xie, S.Q., 2005. Optimal process planning for a combined punch-and-laser cutting machine using ant colony optimization. International Journal of Production Research, 43(11), 2195-2216.

Wang, H., Li, G., and Zhong, Z., 2008. Optimization of sheet metal forming processes by adaptive response surface based on intelligent sampling method. Journal of Materials Processing Technology, 197(1), 77-88.

Wang, L. C., and Lin, S. K., 2009. A multi-agent based agile manufacturing planning and control system. Computers \& Industrial Engineering, 57(2), 620-640.

Wang, L., Yeung, J. H. Y., and Zhang, M., 2011. The impact of trust and contract on innovation performance: The moderating role of environmental uncertainty. International Journal of Production Economics, 134(1), 114-122.

Wu, D., Greer, M. J., Rosen, D. W., and Schaefer, D., 2013. Cloud manufacturing: Strategic vision and state-of-the-art. Journal of Manufacturing Systems, 32(4), 564-579.

Wu, D., Thames, J. L., Rosen, D. W., and Schaefer, D., 2012. Towards a cloud-based design and manufacturing paradigm: looking backward, looking forward. In ASME 2012 International Design Engineering Technical Conferences and Computers and Information in Engineering Conference, 315-328.

Xu, X., 2012. From cloud computing to cloud manufacturing. Robotics and computer-integrated manufacturing, 28(1), 75-86.

Yip, A.L., Jagadeesan, A.P., Corney, J.R., Qin, Y., Rauschecker, U., and Fraunhofer, I., 2011. A front-end system to support cloud-based manfuacturing of customized products. Proceedings of the 9th International Conference on Manufacturing Research ICMR 2011.

Zeng, W., Zhao, Y, and Song, W., 2009. Research on cloud storage architecture and key technologies. Proceedings of the 2nd International Conference on Interaction Sciences: Information Technology ICIS '09, Culture and Human, 1044-1048.

Zhang, L., Luo, Y., Tao, F., Li, B. H., Ren, L., Zhang, X., and Liu, Y., 2014. Cloud manufacturing: a new manufacturing paradigm. Enterprise Information Systems, 8(2), 167-187.

Zhou, J., Yang, H., Wang, M., Jing, S., and Mo, R., 2011. GetCM: a vision of cloud manufacturing. Advanced Materials Research, 213, 388-392. 